\title{
Distribution range shift of two allied species, Nezara viridula and N. antennata (Hemiptera: Pentatomidae), in Japan, possibly due to global warming
}

\author{
Junichi Yukawa, ${ }^{1, *, \dagger}$ Keizi Kiritani, ${ }^{2}$ Naohisa Gyoutoku, ${ }^{3}$ Nami UeChI, ${ }^{4}$ \\ Daisuke YAMAGUCHI ${ }^{1}$ and Satoshi KAMITANI ${ }^{1}$ \\ ${ }^{1}$ Entomological Laboratory, Faculty of Agriculture, Kyushu University; Fukuoka 812-8581, Japan \\ ${ }^{2}$ Futo, Ito, Shizuoka 413-0231, Japan \\ ${ }^{3}$ Yame Center for the Dissemination of Improved Agricultural Methods; Fukuoka 834-0005, Japan \\ ${ }^{4}$ Okinawa Prefectural Agricultural Research Center; Okinawa 901-0336, Japan
}

(Received 8 June 2006; Accepted 21 November 2006)

\begin{abstract}
Intensive and successive field surveys on the relative abundance of Nezara viridula (Hemiptera: Pentatomidae) and $N$. antennata at various localities in northern Kyushu, Japan, together with scattered collection records of $N$. viridula in Kyushu and Honshu, clearly showed that $N$. viridula has been expanding its range northward since the 1960s. The present range of $N$. viridula in Kyushu coincided well with the areas where the mean temperature of the coldest month exceeds $5^{\circ} \mathrm{C}$ that has been suggested to be the lowest thermal limit for $N$. viridula to overwinter successfully. The future range of $N$. viridula is predicted to cover a large area of Kyushu if the temperature rises by 1.4 to $5.8^{\circ} \mathrm{C}$ by 2100 . In some places, $N$. antennata seemed to have been replaced by $N$. viridula as a result of their interspecific mating that prevented $N$. antennata from intraspecific mating. This is because $N$. antennata was overwhelmed, in abundance, by $N$. viridula, which has a higher reproductive potential than $N$. antennata under warm conditions with a sufficient amount of food resources. Conversely, $N$. antennata populations recovered in a few places where $N$. viridula had replaced $N$. antennata in the 1950 s, probably due to the shortage of rice plants on which $N$. viridula preferably reproduces.
\end{abstract}

Key words: Northward range expansion; Nezara viridula; Nezara antennata; global warming; interspecific mating

\section{INTRODUCTION}

Mean global surface temperature has risen by $0.3-0.6^{\circ} \mathrm{C}$ since the late nineteenth century, and has been predicted to rise by $1.4-5.8^{\circ} \mathrm{C}$ by 2100 (Houghton et al., 2001). Such global warming has been considered to influence insect life in various ways (e.g., Kiritani, 1988, 2003, 2006a; Harrington and Stork, 1995; Butterfield and Coulson, 1997; Yamamura and Kiritani, 1998; Hughes, 2000; Yukawa, 2000; McLaughlin et al., 2002; Yukawa and Akimoto, 2006). Among various influences, a poleward range expansion is one of the common trends caused by global warming and has been documented in many insects (e.g., Parmesan and
Yohe, 2003; Root et al., 2003). In Japan, northward expansion has been reported for various butterfly species (e.g., Nakasuji, 1988; Yoshio and Ishii, 2001; Kiritani and Yamamura, 2003) and stink bugs (e.g., Hayashi, 1997; Musolin and Numata, 2003a; Ito, 2004; Kiritani, 2006b). Among stink bugs, the northward range expansion by Nezara viridula (L.) (Hemiptera: Pentatomidae) is particularly a matter of some concern for agricultural production in newly invaded areas because it is one of the serious pests of rice plants and various other crops (e.g., Kiritani, 1971; Todd, 1989). In addition, the northward shift of $N$. viridula involves an interesting ecological aspect of interspecific competition with its allied congener, the oriental green

\footnotetext{
* To whom correspondence should be addressed at: E-mail: JZS02305@nifty.ne.jp

${ }^{\dagger}$ Present address: Matsuzaki 1-5-12, Fukuoka 813-0035, Japan

DOI: 10.1303/aez.2007.205
} 
stink bug, Nezara antennata Scott, which is widely distributed in Japan from Okinawa to Hokkaido, Korea, China, and southeastern Asian countries (e.g., Hayashi, 2002).

$N$. viridula is distributed widely in the tropics, subtropics, and temperate zones of the world (e.g., Yukawa and Kiritani, 1965; Kiritani, 1971; Todd, 1989; Panizzi et al., 2000). In Japan, N. viridula was recorded first in 1874 (location not given) and then in 1879 in Nagasaki Prefecture, Kyushu (Fig. 1) (Hasegawa, 1954). Thereafter, no reliable collection record of $N$. viridula was available in Japan until the 1950s, possibly due to morphological confusion with $N$. antennata. In 1952, its occurrence was confirmed in Kagoshima Prefecture, Kyushu and then in Shikoku and Wakayama Prefecture, Honshu (Fig. 1) (Hasegawa, 1954). N. viridula populations increased in southwestern parts of Japan in the 1950s in association with the prevalence of early-planted rice on which $N$. viridula preferably reproduced (Kiritani, 1971). When the relative abundance of $N$. viridula to $N$. antennata is biased toward one side, interspecific mating between the two bugs, which does not produce fertile eggs, works in favor of the dominant species by reducing the chance of intraspecific mating in the inferior species. According to Kiritani et al. (1963) and Kiritani (1971), N. viridula has higher reproductive potential than $N$. antennata under warm conditions with sufficient amounts of early and late-cultivated rice plants. Therefore, interspecific mating between the two bugs caused a decline of $N$. antennata populations by reducing the chance of intraspecific mating in this species. Thus, $N$. viridula replaced $N$. antennata in many places where the mean temperature of the coldest month exceeds $5^{\circ} \mathrm{C}$, below which $N$. viridula populations hardly persist due to high winter mortality (Kiritani et al., 1963). The two Nezara bugs have been coexisting around the borderline, which is the northern range limit of $N$. viridula.

In the $1960 \mathrm{~s}$, the northern limit of $N$. viridula in Wakayama Prefecture was Arida City (Fig. 1) (Kiritani et al., 1963), but it was found recently in Osaka City (Fig. 1), about $70 \mathrm{~km}$ north of Arida City (unpublished data, see Musolin and Numata, 2003a). On the east coast of Kyushu, the northern limit of N. viridula in 1957 was Takanabe City, Miyazaki Prefecture (1 in Fig. 2) and it had extended northward to Nobeoka City ( 3 and 4 in Fig.
2) by 1960 (Sameshima, 1960). Then, N. viridula was recorded in 1967 from Ume Town and Naokawa Village (5 and 6 in Fig. 2), in the southern parts of Oita Prefecture (Katsunori Tamashima, 2005, personal communication), in 1995 from Saeki City (8 in Fig. 2) (Ministry of Land Infrastructure and Transport, 1997), and in 2003 and 2004 from Oita City (13 in Fig. 2) (Tamashima, 2004).

In the west coast of Kyushu, there was no reliable collection record of $N$. viridula until the 1990s except for one in Nagasaki Prefecture (Fig. 1) in 1879 (Hasegawa, 1954) and observation of its occurrence in rice fields in the Amakusa Islands, $\mathrm{Ku}$ mamoto Prefecture (36 in Fig. 2) in 1965 (Naoyuki Sugiura, 2002, personal communication). In 1993, N. viridula was found in Chuo Town, Kumamoto Prefecture (35 in Fig. 2) and Chikugo City, southern Fukuoka Prefecture (32 in Fig. 2) (Ministry of Land Infrastructure and Transport, 1993). Thereafter, it was collected in 2001 from Uto City, Kumamoto Prefecture (34 in Fig. 2) (Syoiti Miyamoto, 2002, personal communication) and Kurogi Town, southern Fukuoka Prefecture (30 in Fig. 2) (Takafumi Tsutsumi, 2002, personal communication). Quite recently, we became aware of the existence of $N$. viridula in Iwata City, Shizuoka Prefecture, central Honshu (Fig. 1) (Ikeda, 2006). These collection records in recent years suggest that $N$. viridula has been expanding its distribution range northward elsewhere in Japan, as was predicted by Mochida (1991).

In order to confirm the northward expansion of $N$. viridula, we investigated the relative abundance of $N$. viridula and $N$. antennata in various places and gathered scattered information on their existence. This paper intends to (i) clarify the present status of $N$. viridula distribution range by tracing its northward expansion based on field surveys, particularly in Kyushu where recent collection data of the Nezara bugs have accumulated more intensively than in other areas, (ii) discuss the replacement of $N$. antennata by $N$. viridula as a result of their interspecific mating, and (iii) predict the future potential distribution range of $N$. viridula in relation to global warming.

\section{MATERIALS AND METHODS}

Name and position of localities. In 2005, many 
cities and towns were unified into larger cities throughout Japan, following suggestions of the Japanese Government, and new names were often given to the newly unified cities. However, we used the old names of cities and towns before 2005 to express the localities where we surveyed or referred to collection records, because the localities can be more easily identified by old names derived from restricted areas. We indicate the location of respective localities on maps with lines of latitude and longitude (Figs. 1 and 2). In particular, each locality in Kyushu is expressed in the text by the name of the city or town together with a numeral in parentheses that indicates the location of the locality on the map of northern Kyushu (Fig. 2).

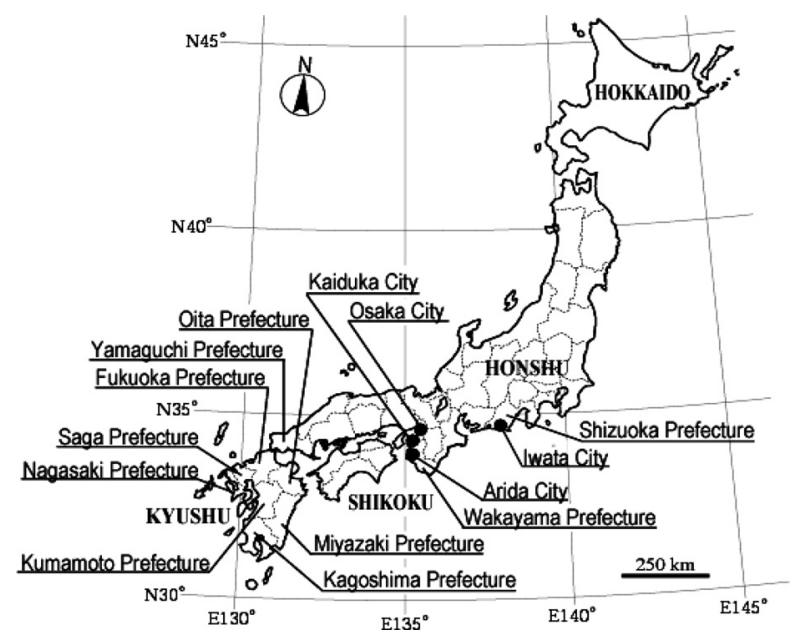

Fig. 1. Map of Japan, excluding the Nansei Islands, indicating prefectures and localities where the presence or absence of Nezara viridula is mentioned in this paper.
Field survey. During the period from 2002 to 2005, we surveyed the relative abundance of $N$. viridula and N. antennata mainly in northern parts of Kyushu, Japan (Fig. 2), where N. viridula had not been found until the 1990s. The localities surveyed intensively were the east coast of Kyushu north of Kadokawa Town, Miyazaki (2-20 in Fig. 2 ), the Chikugo Plains including several cities and towns in southwestern Fukuoka Prefecture (26-33 in Fig. 2), and Munakata and Fukuoka Cities in northern Fukuoka Prefecture (23-25 in Fig. 2). In each locality, 2-5 persons surveyed several fields of different crops and randomly collected adults of $N$. viridula and $N$. antennata by hand, directly from cultivated plants, such as soybean, Glycine max (L.) Merrill; kidney bean, Phaseolus vulgaris L. (Fabaceae); okra, Abelmoschus esculentus Moench (Malvaceae); cucumber, Cucumis sativus L.; bitter gourd, Momordica charantia L. (Cucurbitaceae); tomato, Lycopersicon esculentum Mill. (Solanaceae); sunflower, Helianthus annuus L. (Asteraceae); maize, Zea mays L., and rice plant, Oryza sativa L. (Poaceae). The time devoted to each survey of a crop field varied from one to three hours, depending on the density of the Nezara bugs because their population density was sometimes very low, probably due to the developmental conditions of crops or to the application of insecticides. The two Nezara species collected were brought back to the Entomological Laboratory, Kyushu University, Fukuoka City and identified based on the color of antennae and abdominal tergites (and, if necessary, the paramere of male genitalia), based

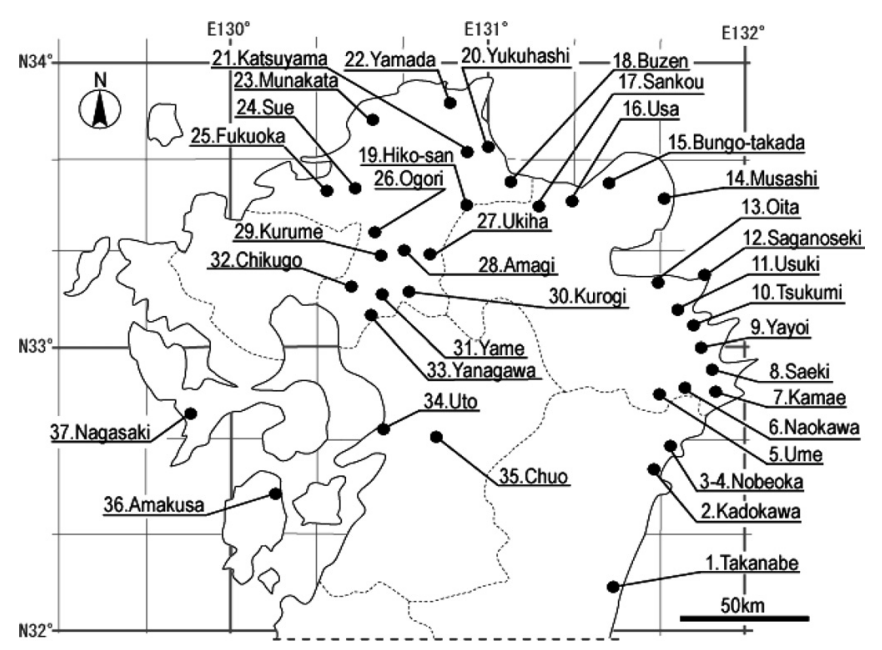

Fig. 2. Map of northern Kyushu, Japan, indicating localities where the presence or absence of Nezara viridula is mentioned in this paper. Each locality is numbered for convenience. 
on the description by Hasegawa (1954) and Kobayashi (1959). When adults were not collected sufficiently, fifth instars, if any, were collected and fed with soybean pods in plastic bags $(400 \mathrm{~mm} \times$ $200 \mathrm{~mm}$ in size) to obtain adult specimens for identification, because the two Nezara bugs could not be distinguished at the larval stage. The aforementioned sampling method was considered not to fail in assessing the relative abundance of $N$. viridula to $N$. antennata, because their adult longevity is long enough to overlap generations, although $N$. viridula has three and $N$. antennata two generations a year (Kiritani et al., 1963). A similar method was applied to assess the relative abundance of $N$. viridula to $N$. antennata at various localities in Wakayama Prefecture (Fig. 1) and its reliability was supported by more intensive ecological surveys on other occasions (Kiritani et al., 1963).

In addition to the aforementioned field survey, we tried to find $N$. viridula in soybean fields in Yamaguchi Prefecture (Fig. 1) and northern Fukuoka Prefecture whenever opportunities arose for field surveys of the soybean pod gall midge, Asphondylia yushimai Yukawa and Uechi (Diptera: Cecidomyiidae) in these areas during the period from 2000 to 2003 (see Fig. 1 in Yukawa et al., 2003). We also occasionally monitored Nezara bugs caught at a light trap sited at the Hiko-san Biological Research Station of the Entomological Laboratory, Kyushu University, Soeda Town, Fukuoka Prefecture (670 m a.s.1.) (19 in Fig. 2).

Nezara bugs were sometimes sent to the Entomological Laboratory, Kyushu University for species identification from various institutions of agriculture in Honshu and Kyushu during the period from 1997 to 2003 because of outbreaks of pentatomids at that time (e.g. Matsumoto et al., 2003). For example, we received, from Mr. K. Tamashima, some specimens of Nezara bugs that had been collected in 1996-1998 from Musashi Town, Oita Prefecture (14 in Fig. 2) and in 2004 from Yayoi Town, Oita Prefecture (9 in Fig. 2). In response to our request, some Nezara specimens were collected in September-October 2002 by Dr. M. Morishita from northern parts of Wakayama Prefecture (Fig. 1) where N. viridula had not been found in the 1961-1962 surveys (Kiritani et al., 1963). We also had an opportunity to survey soybean fields in October 2005 on Jeju Island, Korea, which is located about $100 \mathrm{~km}$ south of the Korean Peninsula and about $230 \mathrm{~km}$ west of northern Kyushu. The island has a mild climate with the mean temperature of the coldest month being about $4^{\circ} \mathrm{C}$.

Changes in the mean temperature for January in Fukuoka Prefecture. First we analyzed the correlation between the annual mean temperature and the monthly mean temperature for January based on meteorological data from 1961 to 1990 at 80 localities in Japan (Japan Meteorological Agency, 1996). After we confirmed that the correlation was supported by a highly significant value, we showed an increasing trend in the monthly mean temperature for January in Fukuoka Prefecture from 1961 to 2000 (Japan Meteorological Agency, 2006).

Future prediction of the distribution range of N. viridula. As mentioned above, it is difficult for $N$. viridula to persist continuously in areas where the mean temperature in the coldest month of the year falls below $5^{\circ} \mathrm{C}$ (Kiritani et al., 1963). Based on this report and the meteorological data for 1961-2005 in Japan (Japan Meteorological Agency, 1996, 2002, 2006), previous, present, and future distribution range maps of $N$. viridula were drawn under the following four different temperature conditions: (1) average temperature in the 1960 s, (2) average temperature in 2001-2005 (present status), which is about $1.0^{\circ} \mathrm{C}$ higher than that in the 1960s (Kiritani, 2006a), (3) temperature about $1.4^{\circ} \mathrm{C}$ higher than that in 1963 (minimum prediction of temperature rising from 1963 to 2100 by Houghton et al., 2001), and (4) temperature about $5.8^{\circ} \mathrm{C}$ higher than 1963 (maximum prediction of temperature rising from 1963 to 2100 by Houghton et al., 2001).

\section{RESULTS}

\section{The east coast of Kyushu north of Kadokawa} Town, Miyazaki Prefecture

Prior to our field surveys, we identified adult specimens that had been collected in 1996-1998 from Musashi Town, Oita Prefecture (14 in Fig. 2) as $N$. viridula. In 2002, only $N$. viridula was found at two localities in Nobeoka City (3 and 4 in Fig. 2, Table 1), where it was first recorded in 1960 (Sameshima, 1960). Our occasional field surveys from 2003 to 2005 also revealed that only $N$. 
Table 1. Relative abundance of $N$. viridula and $N$. antennata at various localities along the east coast of Kyushu, Japan.

Numerals in the column of each Nezara bug indicate the number of Nezara bugs collected from several crop fields in each locality in 2002 and 2004

\begin{tabular}{|c|c|c|c|c|c|c|c|c|c|}
\hline No.* & Locality & 20021 & $N$. antennata & N. viridula & $\%$ & $2004 I$ & N. antennata & N. viridula & $\%$ \\
\hline 3 & Toumi, Nobeoka City, Miyazaki Pref. & 13 July & 0 & 27 & 100 & 5 Nov. & 0 & $>100$ & 100 \\
\hline 4 & Kawashima, Nobeoka City, Miyazaki Pref. & 13 July & 0 & 16 & 100 & 5 Nov. & 0 & $>50$ & 100 \\
\hline 7 & Nagoya, Kamae Town, Oita Pref. & 14 July & 0 & 28 & 100 & & - & - & - \\
\hline 8 & Monzen, Saeki City, Oita Pref. & 14 July & 4 & 11 & 73.3 & & - & - & - \\
\hline 9 & Tokogi, Yayoi Town, Oita Pref. & 14 July & 42 & 11 & 20.8 & & - & - & - \\
\hline 10 & Hikonouchi, Tsukumi City, Oita Pref. & 14 July & 2 & 30 & 93.8 & & - & - & - \\
\hline 11 & Ohno, Usuki City, Oita Pref. & 11 Aug. & 68 & 6 & 8.1 & & - & - & - \\
\hline 12 & $\begin{array}{l}\text { Kouzaki \& Nakahara, Saganoseki Town, } \\
\text { Oita Pref. }\end{array}$ & 12 Aug. & 65 & 0 & $0 \mathrm{a}$ & 27 Sep. & 2 & 25 & $92.6 \mathrm{~b}$ \\
\hline 13 & Sakanoichi, Oita City, Oita Pref. & 11 Aug. & 8 & 11 & $57.9 \mathrm{a}$ & 27 Sep. & 8 & 66 & $89.2 \mathrm{~b}$ \\
\hline 15 & Mori, Bungo-takada City, Oita Pref. & 8 Aug. & 2 & 2 & 50 & & - & - & - \\
\hline 16 & Yokoyama \& Takaya, Usa City, Oita Pref. & 8 Aug. & 156 & 0 & $0 \mathrm{a}$ & 28 Sep. & 16 & 3 & $15.8 \mathrm{~b}$ \\
\hline 17 & Moriyama, Sankou Town, Oita Pref. & 8 Aug. & 87 & 3 & 3.3 & & - & - & - \\
\hline 18 & Yamauchi, Buzen City, Fukuoka Pref. & 8 Aug. & 47 & 0 & 0 & & - & - & - \\
\hline
\end{tabular}

* The numbers indicate the location of each locality on the map of northern Kyushu (Fig. 2).

Different letters on the same line indicate significant difference: $\chi^{2}>\chi_{0.001}^{2}$.

-, Not surveyed.

viridula occurs in Nobeoka City along the coast. The relative abundance of $N$. viridula to $N$. antennata was also $100 \%$ in Kamae Town (7 in Fig. 2), but varied from 3.3 to $93.8 \%$ in seven localities along the east coast of Oita Prefecture (Table 1). No N. viridula was found in Saganoseki Town (12 in Fig. 2), Usa City (16 in Fig. 2), and Buzen City (18 in Fig. 2) in 2002, and around the areas of Yamakuni River Front between Usa City (16 in Fig. 2), and Buzen City (18 in Fig. 2) in the 2003 extensive survey by the Ministry of Land Infrastructure and Transport (1993). Later, N. viridula was found in 2004 in Saganoseki Town (12 in Fig. 2) and Usa City (16 in Fig. 2) for the first time, and the relative abundance of $N$. viridula greatly increased in Oita City (13 in Fig. 2). We also identified specimens collected in 2004 by Mr. K. Tamashima from Yayoi Town, Oita Prefecture (9 in Fig. 2) as N. viridula. In 2004, we found no N. viridula in Katsuyama Town, Fukuoka Prefecture (21 in Fig. 2) that is about $22 \mathrm{~km}$ northwest of Buzen City (18 in Fig. $2)$, but we collected $25 \mathrm{~N}$. viridula adults $(83.3 \%$ of $30)$ in 2005 from the same field. Similarly in Yukuhashi City (20 in Fig. 2) that is about $18 \mathrm{~km}$ northwest of Buzen City (18 in Fig. 2), nine $N$. viridula adults $(81.8 \%$ of 11$)$ and three $N$. antennata adults were collected in 2005. Although Buzen City (18 in Fig. 2) was not surveyed in
$2005, N$. viridula now possibly exists there because it was found in areas (20 and 21 in Fig. 2) north of Buzen City by 2005 .

Thus, compared with the 1960s, the distribution range of $N$. viridula had expanded along the east coast of Kyushu to the northernmost part of Oita Prefecture by 2004 and to the southernmost part of Fukuoka Prefecture by 2005. Subsequently, some places within the $N$. antennata distribution range in northern Miyazaki Prefecture and southern Oita Prefecture appeared to have been taken over by $N$. viridula.

\section{The Chikugo Plains in southern Fukuoka Pre- fecture}

In 2002, the relative abundance of $N$. viridula to $N$. antennata was relatively high in Yame, Chikugo, and Yanagawa Cities (31-33 in Fig. 2), which are located in southern parts of the Chikugo Plains and relatively low in Kurume City and Kurogi Town (29 and 30 in Fig. 2), which are located in central and mountainous parts of the Chikugo Plains, respectively (Fig. 2, Table 2). No $N$. viridula was found in Ogori and Amagi Cities (26 and 28 in Fig. 2 ), which are located in northern parts of the plains. In 2003, the relative abundance of $N$. viridula increased in the southern and central parts of the plains and a few $N$. viridula individuals were 
Table 2. Relative abundance of $N$. viridula and N. antennata at various localities in Chikugo Plains, Fukuoka Prefecture, Japan. Numerals in the column of each Nezara bug indicate the total number of adults collected from several crop fields in each city or town during the summer-autumn of the year

\begin{tabular}{|c|c|c|c|c|c|c|c|c|c|c|}
\hline \multirow{2}{*}{ No.* } & \multirow{2}{*}{ Locality } & \multicolumn{3}{|c|}{2002} & \multicolumn{3}{|c|}{2003} & \multicolumn{3}{|c|}{2005} \\
\hline & & N. antenn & viridula & $\%$ & N. antennata & N. viridula & $\%$ & N. antenn & viridula & $\%$ \\
\hline 26 & Ogori City & 46 & 0 & $0 \mathrm{a}$ & 336 & 2 & $0.8 \mathrm{a}$ & 1 & 1 & $50.0 \mathrm{~b}$ \\
\hline 27 & Ukiha Town & - & - & - & - & - & - & 1 & 6 & 85.7 \\
\hline 28 & Amagi City & 44 & 0 & 0 & 184 & 0 & 0 & - & - & - \\
\hline 29 & Kurume City & 26 & 1 & $3.7 \mathrm{a}$ & 216 & 13 & $5.7 \mathrm{a}$ & 73 & 120 & $62.2 \mathrm{~b}$ \\
\hline 30 & Kurogi Town & 335 & 68 & $16.9 \mathrm{a}$ & 39 & 24 & $38.1 \mathrm{~b}$ & 1 & 7 & $87.5 \mathrm{c}$ \\
\hline 31 & Yame City & 31 & 330 & $91.4 \mathrm{a}$ & 0 & 18 & $100 \mathrm{a}$ & 17 & 172 & $91.0 \mathrm{a}$ \\
\hline 32 & Chikugo City & 7 & 17 & $70.8 \mathrm{~b}$ & 43 & 194 & $81.9 b$ & 0 & 43 & $100 \mathrm{c}$ \\
\hline 33 & Yanagawa City & 11 & 31 & 73.8 & - & - & - & - & - & - \\
\hline
\end{tabular}

* The numbers indicate the location of each locality on the map of northern Kyushu (Fig. 2).

Different letters on the same line indicate significant difference: $\chi^{2}>\chi_{0.001}^{2}$ between $\mathrm{a}$ and $\mathrm{b} ; \chi^{2}>\chi_{0.01}^{2}$ between $\mathrm{b}$ and $\mathrm{c}$. —, Not surveyed.

found in Ogori City (26 in Fig. 2), in the northern Chikugo Plains. In 2005, the relative abundance of $N$. viridula increased at almost all localities surveyed (Table 2). In addition, $N$. viridula was found in Ukiha Town (27 in Fig. 2), a mountainous area of the plains. These data indicate that, in recent years, $N$. viridula has been expanding its distribution range northward and into mountainous areas in the Chikugo Plains (26-33 in Fig. 2). Amagi City (28 in Fig. 2) was not surveyed in 2005, but $N$. viridula might have reached there because it was found in two adjacent areas, Ogori City (26 in Fig. 2) and Ukiha Town (27 in Fig. 2) in 2005.

\section{Northern Fukuoka Prefecture and Yamaguchi Prefecture}

$N$. viridula was not found in an intensive field survey of Yamada Park, Kitakyushu City (22 in Fig. 2) (Saigusa et al., 1992) and around the areas of the Onga River Front near Munakata City (23 in Fig. 2) (Ministry of Land Infrastructure and Transport, 1993). All 25 Nezara specimens collected in July 2002 from Motooka, Nishi Ward, Fukuoka City (25 in Fig. 2) were N. antennata. Until 2003, $N$. viridula was not found in either northern Fukuoka Prefecture or Yamaguchi Prefecture, Honshu (Fig. 1) even though soybean fields were intensively surveyed on many occasions in search of the soybean pod gall midge, A. yushimai, by two authors, JY and NU (Yukawa et al., 2003). No $N$. viridula specimens or reports of its collection were sent to the laboratory until 2003 from any of the agricultural experimental stations in northern Kyushu and, until now, from those of Yamaguchi Prefecture (Fig. 1), with which the laboratory has a close relationship through species identification services. In addition, until now, $N$. viridula has not been caught at a light trap sited at the Hiko-san Biological Research Station (19 in Fig. 2) located in a mountainous area of Fukuoka Prefecture.

In September 2003, two N. viridula adults were collected from Sue Town (24 in Fig. 2), a southern suburb of Fukuoka City, and 11 adults from Sawara Ward of Fukuoka City (25 in Fig. 2). On 3 October 2005, 22 and 70 adults of $N$. viridula and $N$. antennata were found, respectively, in soybean fields in Munakata City (23 in Fig. 2), where no N. viridula was found in our 2004 survey. These data may indicate that $N$. viridula arrived recently in the northern parts of Fukuoka Prefecture (23-25 in Fig. 2).

\section{Areas other than Kyushu and Yamaguchi Pre- fecture}

Four N. viridula adults were found among 14 Nezara specimens that had been collected by Dr. M. Morishita in 2002 from several areas in northern Wakayama Prefecture (Fig. 1) where $N$. viridula was not previously distributed (Kiritani et al., 1963). The infestation of eggplants by $N$. viridula was found in 2003 at Kaiduka City (Fig. 1 ), which is located between Wakayama and Osaka Cities (Hiroshi Tanaka, 2006, personal communication). These findings indicate the possibility that N. viridula occurs continuously from Wakayama 
Prefecture to Osaka City (Fig. 1) where $N$. viridula was found in recent years (unpublished data, see Musolin and Numata, 2003a). More recently, it was recorded in Iwata City, Shizuoka Prefecture, Central Honshu, $210 \mathrm{~km}$ east of Osaka City (Fig. 1) (Ikeda, 2006).

It should be remarked here that on Jeju Island, Korea, 13 and 20 adults of $N$. antennata were observed, respectively, in soybean fields at $\mathrm{Su}-\mathrm{San}$ on 17 October 2005 and at Hae-An Dong on 18 October 2005 , but no $N$. viridula adults were found in the fields. On Jeju Island, the mean temperature in the coldest month is about $4^{\circ} \mathrm{C}$, which is slightly lower than the temperature that allows $N$. viridula to overwinter.

Another interesting piece of distributional information on the two stink bugs is that $N$. antennata populations recovered in some places in southern Wakayama Prefecture where N. viridula had once replaced the range of $N$. antennata in the $1950 \mathrm{~s}$ (Goto, 2001).

\section{Inter- and intraspecific mating}

In addition to intraspecific mating, two combinations of interspecific mating between $N$. viridula and $N$. antennata males and females were sometimes observed in the fields throughout the 2002 to 2005 surveys at almost all localities in Oita and Fukuoka Prefectures where the two species were coexisting (Table 1). Interspecific mating was also observed occasionally in the plastic bags $(400 \times$ $200 \mathrm{~mm}$ in size) in which they were brought back to the laboratory. These observations indicate that interspecific mating is common between the two Nezara bugs, as has been noted in Kiritani et al. (1963).

\section{Changes in the mean temperature for January in Fukuoka Prefecture}

The correlation between the annual mean temperature and the monthly mean temperature for January was supported by a highly significant value (Fig. 3). According to meteorological data in Fukuoka Prefecture for 40 years from 1961 to 2000 , the coldest monthly mean temperature of the year was recorded 25 times in January and 15 in February (Japan Meteorological Agency, 2006). We therefore regarded January as the coldest month and detected an increasing trend in the monthly mean temperature for January in Fukuoka

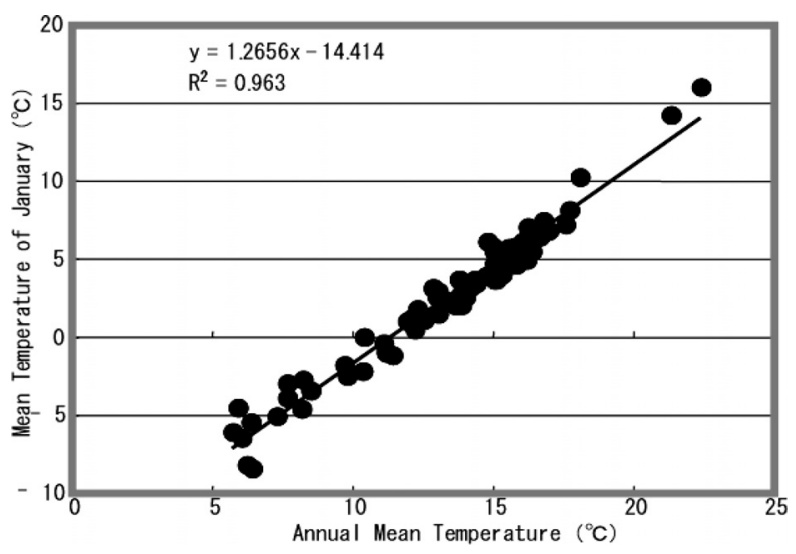

Fig. 3. Correlation between the annual mean temperature and monthly mean temperature for January from 1961 to 1990.

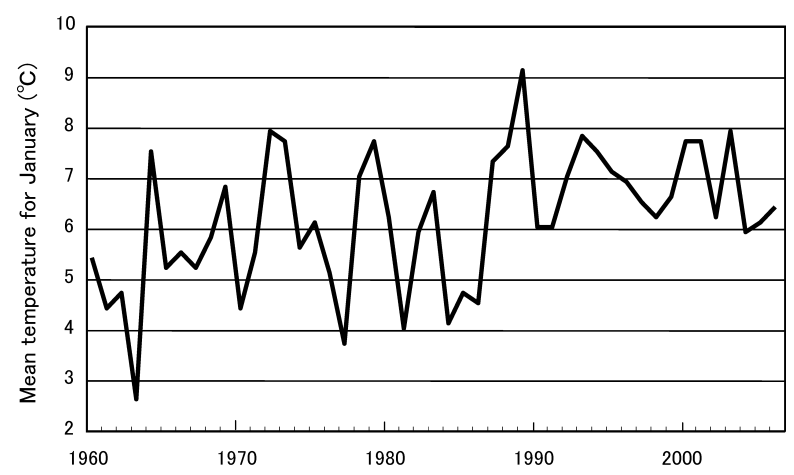

Fig. 4. An increasing trend in the monthly mean temperature for January in Fukuoka Prefecture from 1961 to 2000.

Prefecture from 1961 to 2000 (Fig. 4). The mean temperature for January frequently dropped below $5^{\circ} \mathrm{C}$ until 1986 , but it always exceeded $5^{\circ} \mathrm{C}$ thereafter.

\section{Future prediction of the distribution range of $N$. viridula}

In the early $1960 \mathrm{~s}$, the mean surface temperature was about $1.0^{\circ} \mathrm{C}$ lower than in 2001-2005 (Table $3)$; therefore, the areas where the mean temperature of the coldest month is high enough for $N$. viridula to overwinter were limited (Fig. 5A). These areas coincided with the range of $N$. viridula at that time, as has been noted by the scattered collection records. By 2001-2005, areas with a mean winter temperature exceeding $5^{\circ} \mathrm{C}$ expanded (Fig. 5B), and now overlap the actual range of $N$. viridula surveyed recently in Kyushu (Fig. 2). The future potential range of $N$. viridula is predicted to cover a large area of Kyushu if the temperature rises by 1.4 
Table 3. Changes of yearly mean temperature* in Kyushu from the early 1960 s up to the present

\begin{tabular}{lccc}
\hline Prefecture** & 1961-1965 & 1971-2000 & 2001-2005 \\
\hline Fukuoka & 16.0 & 16.6 & 17.3 \\
Nagasaki & 16.7 & 16.9 & 17.5 \\
Saga & 16.7 & 16.3 & 16.9 \\
Kumamoto & 16.1 & 16.5 & 17.4 \\
Oita & 15.6 & 16.0 & 16.9 \\
Miyazaki & 16.9 & 17.3 & 17.9 \\
Kagoshima & 17.2 & 18.0 & 18.9 \\
\hline Mean & 16.5 & 16.8 & 17.5 \\
\hline
\end{tabular}

* Temperatures in the city where the main office of each prefecture is located.

** See Fig. 1 for the location of each prefecture.
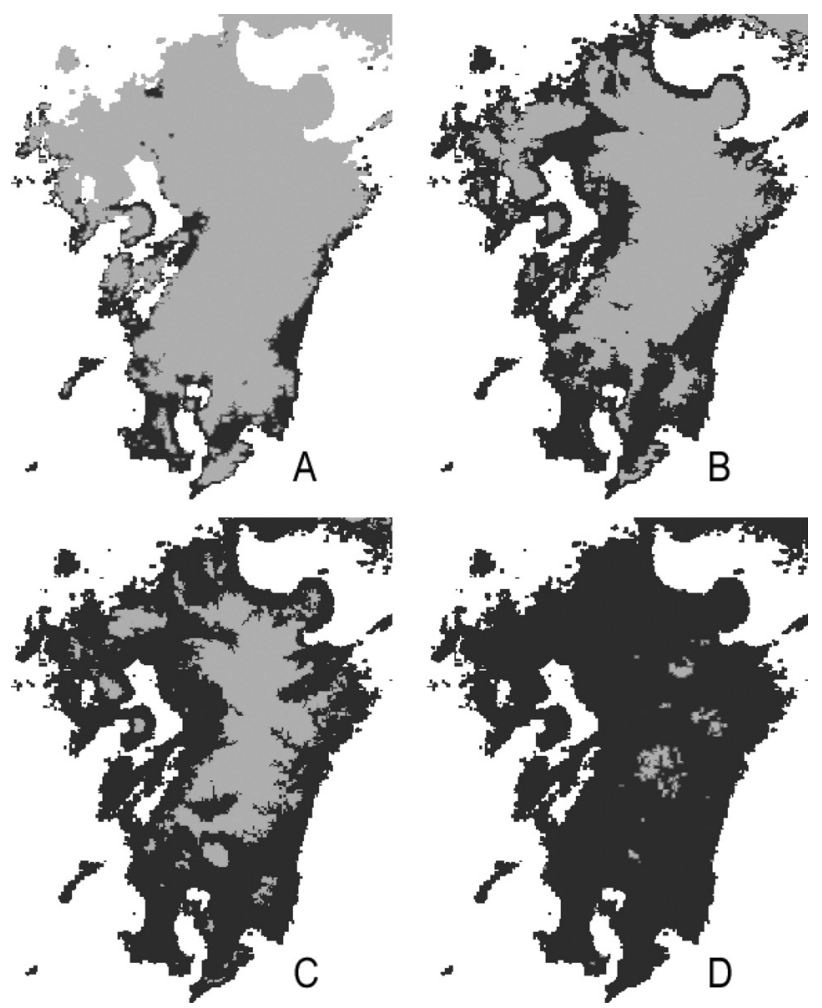

Fig. 5. Previous, present, and future distribution range maps of Nezara viridula in Kyushu, Japan, indicated as darkened areas where the mean temperature of the coldest month exceeds $5^{\circ} \mathrm{C}$, allowing $N$. viridula to overwinter. The maps were drawn based on the following four different temperature conditions: (A) average temperature in the 1960s, (B) average temperature in 2001-2005 (present status), which is about $1.0^{\circ} \mathrm{C}$ higher than in the $1960 \mathrm{~s}$, (C) temperature about $1.4^{\circ} \mathrm{C}$ higher than in 1963 (minimum prediction of temperature rising from 1963 to 2100 by Houghton et al., 2001), and (D) temperature about $5.8^{\circ} \mathrm{C}$ higher than 1963 (maximum prediction of temperature rising from 1963 to 2100 by Houghton et al., 2001). or $5.8^{\circ} \mathrm{C}$ by 2100 (Fig. $\left.5 \mathrm{C}, \mathrm{D}\right)$.

\section{DISCUSSION}

\section{Northward expansion of distribution range by N. viridula}

Meteorological data have indicated a trend of rising temperature in recent years (Japan Meteorological Agency, 2006). In particular, the mean temperature for January in Fukuoka Prefecture has never dropped below $5^{\circ} \mathrm{C}$ since 1986 (Fig. 4), which means that $N$. viridula can now overwinter in northern Kyushu. The field data obtained in this study clearly show that $N$. viridula has been expanding its range northward since the 1960s. In addition, the actual range of $N$. viridula surveyed recently in Kyushu (Fig. 2) coincided well with areas where the mean temperature of the coldest month now exceeds $5^{\circ} \mathrm{C}$ (Fig. 5B). This suggests that prediction based on the temperature is fairly reliable and that global warming has been facilitating range expansion of $N$. viridula to more northern areas where it could not overwinter previously. Although we have no actual data, this trend may be attributed not only to Kyushu but also to other areas of Shikoku and Honshu as $N$. viridula has already been found in Osaka and Shizuoka Prefectures. However, $N$. viridula has not yet arrived at every edge of its potential distribution range (Fig. 5B). A mark and recapture study conducted by Kiritani et al. (1961) demonstrated that $N$. viridula adults were able to locate host rice plants within 24 $\mathrm{h}$ even when they were released $1 \mathrm{~km}$ away from the rice field. Therefore, the time lag between the rise of temperature and the range shift of $N$. viridula could be explained by the time required for $N$. viridula to increase its number enough to be detectable in the field.

In the course of poleward expansion by $N$. viridula, it should be noted that its initial establishment is often prevented by interspecific mating in newly invaded areas where $N$. antennata is predominant. Range expansion could occur more easily when geographical barriers do not exist between the original source areas and the potential distribution range.

The urban heat island effect may also allow $N$. viridula to overwinter when it is accidentally introduced into a large city located far north of the original source area. Recently, three colonies of $N$. 
viridula have been found feeding on tomatoes in London, UK (BBC News, 17 June 2004), although there has been no record of $N$. viridula in the UK for the past 40 years. Recent increases of crop and vegetable importation from the Subtropical and Tropical Regions would provide pest insects, such as $N$. viridula, with frequent opportunities to expand their distribution range polewards (Kiritani, 2003).

\section{Replacement of $N$. antennata distribution range by $N$. viridula}

In northern parts of Miyazaki Prefecture (Table 1) and some areas in the Chikugo Plains, Fukuoka Prefecture (Table 2), the southern range limit of $N$. antennata seems to have retreated locally from south to north and its former range has been replaced by $N$. viridula. Examples of retreating from south to north have been relatively few compared to those of northward expansion (Parmesan et al., 1999) and the reasons for retreating have seldom been explained. In the case of N. antennata, as has been demonstrated in Kiritani et al. (1963), interspecific mating between the two Nezara species might play an important role in replacement under conditions of higher relative abundance of $N$. viridula than $N$. antennata, caused by the greater reproductive ability of the former. In addition, summer aestivation that limits the number of annual generations (Noda, 1984) could be disadvantageous to $N$. antennata under global warming. Therefore, if the temperature keeps rising, such replacement will occur also in other areas where the two species are now coexisting and $N$. antennata will become extinct by 2100 from many areas, except high mountainous areas, if the temperature rises by 1.4 (Fig. $5 \mathrm{C}$ ) to $5.8^{\circ} \mathrm{C}$ (Fig. 5D).

\section{Coexistence of the two Nezara bugs in relation to overwintering success}

The coexistence of the two Nezara bugs around the isometric line of $5^{\circ} \mathrm{C}$ as the mean temperature of the coldest month has been explained by seasonal changes in the relative abundance of $N$. viridula to $N$. antennata due to the higher reproductive rate in spring-autumn and low survival rate in winter in $N$. viridula populations (Kiritani et al., 1966). In addition, $N$. viridula seems more susceptible to variable winter conditions than $N$. antennata. For example, the relative abundance of over- wintered $N$. viridula to $N$. antennata was $63.8 \%$ in the spring of 1962 , but it fell to $4.2 \%$ after the severe winter of 1963 (Kiritani, 1965). In every late March from 1962 to 1967, Kiritani et al. (1966) and Kiritani (1971) examined the winter mortality of $N$. viridula adults and obtained a regression line, $Y=-16.45 X+147.08\left(R^{2}=0.6127, p<0.0001\right)$, between mortality $(Y)$ and the mean temperature in January $(X)$. This suggests that every $1{ }^{\circ} \mathrm{C}$ rise within a limited range would result in a decrease in winter mortality of about $16.5 \%$ in $N$. viridula, provided that $X$ varies from 3 to $7^{\circ} \mathrm{C}$ (Kiritani, $2006 \mathrm{a}, \mathrm{b})$. Therefore, winter mortality would become about $65 \%$ around the northern range limit of $N$. viridula defined by the isometric line of $5^{\circ} \mathrm{C}$ as the mean temperature of the coldest month.

The physiological and ecological backgrounds of winter mortality and subsequent performance have been demonstrated to be related to the early entrance to diapause to avoid untimely late-autumn reproduction (Musolin and Numata, 2003b). Unless the winter temperature becomes high enough to reduce the winter mortality of $N$. viridula, the two Nezara bugs will continue to coexist around the border.

Even in areas where winter temperature is sufficiently high for $N$. viridula to overwinter, the two Nezara bugs may continue to coexist, as shown in the southward range shift by $N$. antennata in southern parts of Wakayama Prefecture (Fig. 1) (Goto, 2001). We consider that interspecific mating between the two Nezara species cannot play an important role in replacement, possibly because the reproductive ability of $N$. viridula is limited in areas where rice fields have been reduced and the rice-cultivating season has been shortened. Under such conditions, the two species may also coexist elsewhere in Japan because $N$. viridula has been known to reproduce preferably on rice rather than other crops (Kiritani et al., 1963).

\section{Effects of global warming on other aspects of $N$. viridula than northward shift}

Based on the lower developmental zero point of various species and thermal totals above the zero point that are required to complete one generation, Kiritani (2006a) predicted that, when the mean surface temperature rises by $2.0^{\circ} \mathrm{C}$, most insect predator and parasitoid groups will produce an additional 2-4 generations each year, while most rice 
pests will increase at most by one generation, except for mirids and delphacids (Hemiptera). Following his prediction, $N$. viridula has the potential to increase by only one generation a year, while its egg parasitoids increase by two or more generations. There is still uncertainty regarding the extent to which host-parasitoid phenology synchronizes after an increase in generations. This means that natural control of $N$. viridula by egg parasitoids is expected to be more effective, resulting in a lower density in the future.

Yukawa (2000) and Yukawa and Akimoto (2006) emphasized that climate change would lead to asynchrony between the appearance of herbivorous insects and their host plant phenology, particularly in short-lived and mono- or oligophagous insects such as gall midges. However, asynchrony may cause little damage to $N$. viridula because of its extremely wide host plant range and long adult life span of at least a month.

\section{ACKNOWLEDGEMENTS}

We wish to thank Messrs. K. Tamashima, S. Okazaki, H. Yoshimatsu (Oita Prefectural Agriculture, Forestry and Fisheries Research Center), Dr. M. Morishita (Wakayama Research Center of Agriculture, Forestry and Fisheries), Prof. J.C. Paik (Sunchon National University), and Miss T. Ganaha, Miss C. Okamoto, and Mr. N. Wachi (Kyushu University) for their assistance in collecting or rearing the Nezara bugs. Dr. K. M. Harris (former Director of IIE, UK), to whom we are deeply indebted, read through an early draft of this paper and gave us information on $N$. viridula in London. Our thanks are also due to Prof. S. Miyamoto, Dr. T. Tsutsumi, Mr. N. Sugiura, and Mr. F. Ikeda for their information on the collection records of $N$. viridula. This study was supported by a Grant-inAid for Scientific Research from the Japan Ministry of Education, Science and Culture to JY (No. 11308021). This study was also supported partly by the Research Fellowship of the Japanese Society for the Promotion of Sciences for Young Scientists to NU. This is a contribution from the Entomological Laboratory, Faculty of Agriculture, Kyushu University, Fukuoka (series 6, No. 28).

\section{REFERENCES}

BBC News (2004) Insect enjoys warmer UK climate. Story from BBC News 17 June 2004. http://news.bbc.co.uk/go/ $\mathrm{pr} / \mathrm{fr} /-/ 2 / \mathrm{hi} / \mathrm{science} /$ nature/3815833.stm

Butterfield, J. E. L. and J. C. Coulson (1997) Terrestrial invertebrates and climate change: physiological and lifecycle adaptations. In Past and Future Rapid Environmental Changes: The Spatial and Evolutionary Responses of Terrestrial Biota (B. Huntley, W. Cramer, A. V. Morgan, H. C. Prentice and J. R. Allen eds.). Springer, Berlin, pp. 401-412.

Goto, S. (2001) Rerecorded and additional collection data of
Heteroptera in Wakayama Prefecture 4. Kinokuni 59: 16 (in Japanese).

Harrington, R. and N. E. Stork (1995) Insects in a Changing Environment. Academic Press, London. 535 pp.

Hasegawa, H. (1954) Notes on Nezara viridula (Linné) and its allied green stink-bugs in Japan. Bull. Natl. Inst. Agric. Sci., Ser. C 4: 215-228 (in Japanese with English summary).

Hayashi, H. (1997) Historical changes and control of rice stink bug complex causing the pecky rice. Plant Prot. 51: 455-461 (in Japanese).

Hayashi, M. (2002) Heteroptera. In Check List of the Insect of the Ryukyu Islands. 2nd ed. (S. Azuma ed.). The Biological Society of Okinawa, Naha, Okinawa, pp. 127-149.

Houghton, J. T., Y. Ding, D. J. Griggs, M. Noguer, P. J. van der Linden, X. Dai, K. Maskell and C. A. Johnson (2001) Climate Change 2001: The Scientific Basis. Cambridge University Press, Cambridge. 944 pp.

Hughes, L. (2000) Biological consequences of global warming: is the signal already apparent? Trend. Ecol. Evol. 15: 56-61.

Ikeda, M. (2006) First occurrence of Nezara viridula in Shizuoka Prefecture. Shizuoka Newspaper 29 March 2006 (in Japanese).

Ito, K. (2004) The role of feeding habits of Trigonotylus caelestialium (Kirkaldy) (Heteroptera: Miridae) on the production of pecky rice grains with special reference to the occurrence of split-hull paddy. Jpn. J. Appl. Entomol. Zool. 48: 23-32 (in Japanese with English summary).

Japan Meteorological Agency (1996) CD-ROM: Normals for the period 1961-1990.

Japan Meteorological Agency (2002) CD-ROM: Normals for the period 1971-2000.

Japan Meteorological Agency (2006) Information on Meteorological Statistics: Meteorological Observation. http:// www.data.kishou.go.jp/etrn/index.html (in Japanese).

Kiritani, K. (1965) Factors determining the distribution of the two related stink bugs, Nezara viridula L. and N. antennata Scott. In Proceedings of the XII International Congress of Entomology, London. 1964 (P. Freeman ed.). The Royal Entomological Society of London, London, p. 423.

Kiritani, K. (1971) Distribution and abundance of the southern green stink bug, Nezara viridula. In Proceedings of the Symposium on Rice Insects. Tropical Agricultural Research Center, MAF, Tokyo, pp. 235-248.

Kiritani, K. (1988) Effects of climate change on the insect fauna. Meteorol. Res. Rep. 162: 137-341 (in Japanese).

Kiritani, K. (2003) Invasive alien species issues. In Forest Insect Population Dynamics and Host Influences. Proceedings of IUFRO Kanazawa 2003 (N. Kamata, A. M. Liebhold, D. T. Quiring and K. M. Clancy eds.). Kanazawa University, Kanazawa, pp. 6-10.

Kiritani, K. (2006a) Predicting impacts of global warming on population dynamics and distribution of arthropods in Japan. Popul. Ecol. 48: 5-12.

Kiritani, K. (2006b) The impact of global warming and landuse change on the pest status of rice and fruit bugs (Het- 
eroptera) in Japan. Global Change Biol. (in press).

Kiritani, K., N. Hokyo and S. Enomoto (1961) The role played by the early planting rice in the population increase of the southern green stink bug. Kansai Byogaichu Kenkyu 3: 50-55 (in Japanese).

Kiritani, K., N. Hokyo and K. Kimura (1966) Factors affecting the winter mortality in the southern green stink bug, Nezara viridula L. Ann. Soc. Entomol. Fr., Nouv. Sér. (Sunn Pest Memoirs 9) 2: 199-207.

Kiritani, K., N. Hokyo and J. Yukawa (1963) Co-existence of the two related stink bugs, Nezara viridula and $N$. antennata under natural conditions. Res. Popul. Ecol. 5: 1122.

Kiritani, K. and K. Yamamura (2003) Exotic insects and their pathways for invasion. In Invasive Species: Vectors and Management Strategies (G. M. Ruiz and J. T. Carlton eds.). Island, Washington, D. C., pp. 44-67.

Kobayashi, T. (1959) The developmental stages of some species of the Japanese Pentatomidae (Hemiptera). VII. Jpn. J. Appl. Entomol. Zool. 3: 221-231 (in Japanese with English summary).

Matsumoto, S., K. Yamada, T. Hata and E. Michitani (2003) Outbreaks of fruit-infesting stink bugs in Fukuoka prefecture in 2002 and factors responsible. Kyushu Plant Prot. Res. 49: 111-115 (in Japanese).

McLaughlin, J. F., J. J. Hellmann, C. L. Boggs and P. R. Ehrlich (2002) Climate change hastens population extinctions. Proc. Natl. Acad. Sci. USA 99: 6070-6074.

Ministry of Land Infrastructure and Transport (1993) A Yearbook of National Census on River Environments in 1991, Researches on Benthos, Birds, Amphibian, Reptiles, Mammals, and Terrestrial Insects. Foundation for Riverfront Improvement and Restoration, Tokyo. 999 pp. (in Japanese).

Ministry of Land Infrastructure and Transport (1997) A Yearbook of National Census on River Environments in 1995, Researches on Benthos, Birds, Amphibian, Reptiles, Mammals, and Terrestrial Insects. Foundation for Riverfront Improvement and Restoration, Tokyo. CDROM+77 pp. (in Japanese).

Mochida, O. (1991) Impact of $\mathrm{CO}_{2}$-associated climate change on pest distribution. Nôgyô oyobi Engei 66: 128-136 (in Japanese).

Musolin, D. and H. Numata (2003a) Photoperiodic and temperature control of diapause induction and colour change in the southern green stink bug Nezara viridula. Physiol. Entomol. 28: 65-74.

Musolin, D. and H. Numata (2003b) Timing of diapause induction and its life-history consequences in Nezara viridula: is it costly to expand the distribution range? Ecol. Entomol. 28: 694-703.

Nakasuji, F. (1988) Migration of butterflies and its evolutionary adaptation. Special Issue Jpn. Soc. Lepidoptera 6: 211-249.

Noda, T. (1984) Short day photoperiod accelerates the oviposition in the Oriental green stink bug, Nezara antennata Scott (Heteroptera: Pentatomidae). Appl. Entomol.
Zool. 19: 119-120.

Panizzi, A. R., J. E. McPherson, D. G. James, M. Javahery and R. M. McPherson (2000) Stink bugs (Pentatomidae). In Heteroptera of Economic Importance (C. W. Schaefer and A. R. Panizzi eds.). CRC Press, Boca Raton, Florida, pp. $421-474$.

Parmesan, C., N. Ryrholm, C. Stefanescu, J. K. Hill, C. D. Thomas, H. Descimon, B. Huntley, L. Kaila, J. Kullberg, T. Tammaru, J. Tennent, J. A. Thomas and M. Warren (1999) Poleward shift in geographical rages of butterfly species associated with regional warming. Nature 399: 579-583.

Parmesan, C. and G. Yohe (2003) A globally coherent fingerprint of climate change impacts across natural systems. Nature 421: 37-42.

Root, T. L., J. T. Price, K. R. Hall, S. H. Schneider, C. Rosenzweig and J. A. Pounds (2003) Fingerprints of global warming on wild animals and plants. Nature 421: $57-60$.

Saigusa, T., T. Kawamura, O. Yata, K. Ueda, Y. Shinkai, I. Tabata, T. Yasunaga, S. Kamitani, S. Nomura, Y. Sawada, K. Yahiro, M. Koge, M. Ueda, K. Sasaki, E. Fujiyoshi, K. Sawada, S. Yamane and C. Shirôzu (1992) The insects and their environments of Yamada Park, Kitakyushu. In Nature of Yamada Park, Kitakyushu City, Japan (M. Ota et al. eds.). Kitakyushu Museum of Natural History, Kitakyushu, Japan, pp. 77-159 (in Japanese with English summary).

Sameshima, T. (1960) Infestation and damage caused by the southern green stink bug. Plant Prot. 14: 242-246 (in Japanese).

Tamashima, K. (2004) Collection records of Nezara viridula from Oita City. Nihô no Mushi 41: 27 (in Japanese).

Todd, J. W. (1989) Ecology and behavior of Nezara viridula. Annu. Rev. Entomol. 34: 273-292.

Yamamura, K. and K. Kiritani (1998) A simple method to estimate the potential increase in the number of generations under global warming in temperate zones. Appl. Entomol. Zool. 33: 289-298.

Yoshio, M. and M. Ishii (2001) A phenological study on northward invasion of the great mormon, Papilio memnon L. Jpn. J. Ecol. 51: 125-130 (in Japanese with English summary).

Yukawa, J. (2000) Synchronization of gallers with host plant phenology. Popul. Ecol. 42: 105-113.

Yukawa, J. and K. Akimoto (2006) Influence of synchronization between adult emergence and host plant phenology on the population density of Pseudasphondylia neolitseae (Diptera: Cecidomyiidae) inducing leaf galls on Neolitseae sericea (Lauraceae). Popul. Ecol. 48: 13-21.

Yukawa, J. and K. Kiritani (1965) Polymorphism in the southern green stink bug. Pacific Insects 7: 639-642.

Yukawa, J., N. Uechi, M. Horikiri and M. Tuda (2003) Description of the soybean pod gall midge, Asphondylia yushimai sp. n. (Diptera: Cecidomyiidae), a major pest of soybean and findings of host alternation. Bull. Entomol. Res. 93: 73-86. 